\title{
Avaliação da biossegurança em estabelecimentos de aplicação de maquiagem
}

\section{Biosafety assessment in establishments for makeup application}

Recebido em: 08/03/2018 Aceito em: $07 / 08 / 2018$
Vanessa Cavanus FOPPA ${ }^{1}$; Matias TIECHER ${ }^{2}$; Renata Vidor CONTRI ${ }^{1}$ ${ }^{1}$ Universidade do Vale do Taquari-UNIVATES. Avenida Avelino Talini, 17, Bairro Universitário, CEP 95914-014. Lajeado, Rio Grande do Sul, Brasil. ${ }^{2}$ Universidade Federal do Rio Grande do Sul - UFRGS. Avenida Paulo Gama, 110, Bairro Farroupilha, CEP 90040-060. Porto Alegre, Rio Grande do Sul, Brasil.

E-mail: vanessacfoppa@gmail.com

\section{ABSTRACT}

The shared use of instruments for aesthetic procedures can result in contamination of both the utensils and the cosmetic that will be used in its original packaging and can be a source of disease transmission. This work aimed to evaluate the level of information that make-up professionals possess, through the application of a questionnaire about the biosafety measures inherent to the activities performed and also to determine the presence or absence of pathogenic bacteria in instruments used in makeup procedures, correlating the results found with the questionnaire responses. Five establishments participated in the research, each of which provided two devices for the application of makeup to try to isolate the bacteria Staphylococcus aureus and Pseudomonas aeruginosa. Also, each establishment presented a makeup professional to answer the questionnaire involving biosafety. There was no growth of the bacteria studied in the analyzed samples. However, one of them developed colonies compatible with Staphylococcus epidermidis. Regarding the questionnaire, some of the professionals' answers indicated nonconformity with the legislation, such as the lack of EPI, the lack of a specific place for washing the materials, and the absence of enzymatic detergent for the cleaning of the makeup instruments, which indicates a higher risk of contamination. We can conclude that the bacteria of interest were not found in the samples, although the professionals of the establishments answered that they do not comply with some biosafety measures. However, it should be considered the possibility of other potentially pathogenic bacteria or fungi present in them.

Keywords: Biosafety; makeup; contamination

\section{RESUMO:}

O uso compartilhado de instrumentos em procedimentos estéticos pode resultar na contaminação tanto dos utensílios, quanto do cosmético que será utilizado em sua embalagem original, podendo ser fonte de transmissão de doenças. Este trabalho teve como objetivo avaliar o nível de informação que as maquiadoras possuem, utilizando a aplicação de um questionário, com relação às medidas de biossegurança inerentes às atividades realizadas, e também determinar a presença ou ausência de bactérias patogênicas em artigos utilizados em procedimentos de maquiagem, correlacionando os resultados encontrados com as respostas do questionário. Cinco estabelecimentos prestadores de serviços de maquiagem participaram da pesquisa, sendo que cada um forneceu dois artigos para aplicação de maquiagem, para tentativa de isolamento das bactérias Staphylococcus aureus e Pseudomonas aeruginosa. Além disso, cada estabelecimento apresentou um profissional maquiador para responder ao questionário com perguntas envolvendo biossegurança. Não houve crescimento das bactérias pesquisadas nas amostras analisadas; porém, uma delas apresentou desenvolvimento de colônias compatíveis com Staphylococcus epidermidis. Com relação ao questionário, algumas respostas dos profissionais apontaram não conformidades com a legislação, como a falta do uso de EPI, a falta de um 
local específico para limpeza do material, e a ausência do detergente enzimático na limpeza dos artigos de maquiagem, o que indica maior risco de contaminação. Não foram encontradas as bactérias de interesse nos artigos de maquiagem, apesar dos profissionais dos estabelecimentos responderem que não cumprem algumas medidas de biossegurança. Contudo, não está descartada a possibilidade de haver outras bactérias ou fungos potencialmente patogênicos presentes no material utilizado nos procedimentos.

Palavras-chave: biossegurança; maquiagem; contaminação.

\section{INTRODUÇÃO}

A preocupação com a beleza, a saúde e o envelhecimento é um dos principais marcos da sociedade atual. Neste contexto sociocultural, a maquiagem ocupa um lugar de destaque, onde as mulheres contam com uma ampla gama de recursos estéticos e de alta tecnologia (1). Diversos estabelecimentos, que envolvem desde clínicas a salões de beleza, oferecem procedimentos estéticos, incluindo aplicação de maquiagem, englobando profissionais com formação em diferentes áreas. Esses procedimentos são cada vez mais acessíveis ao público geral, alcançando variadas classes sociais. Os riscos relacionados a esses procedimentos, como a transmissão de doenças, aumentam quando há falta de informação por parte do consumidor, infraestrutura e equipamentos inadequados, baixa qualificação e despreparo do profissional, falhas no reprocessamento do material utilizado nesses procedimentos e, principalmente, quando os investimentos têm o objetivo de atrair o consumidor e não de garantir sua saúde e segurança, bem como do próprio prestador do serviço (2).

A biossegurança, segundo Teixeira e Valle (1996), é definida pela "condição de segurança alcançada por um grupo de ações destinadas a prevenir, controlar, reduzir ou eliminar riscos próprios às atividades que possam comprometer a saúde humana, animal ou o meio ambiente" (3). A adoção de medidas relacionadas à biossegurança requer profissionais capacitados, com princípios éticos e científicos, que não tenham como objetivo apenas parecer corretos, para ganhar uma falsa credibilidade para o seu trabalho, mas sim, que estejam engajados em reduzir os riscos biológicos, físicos, químicos, de acidentes e ergonômicos inerentes à profissão (4).

As normas e condutas de biossegurança, são bem estabelecidas para estabelecimentos de saúde, tais como hospitais, consultórios médicos, odontológicos, laboratórios, entre outros. Contudo, há necessidade de legislações e normativas para a área da estética e embelezamento. Segundo Garbaccio e Oliveira (2013), não há uma regulamentação nacional para os profissionais da beleza e estética (2). Por isso, Schwaab e cols (2018) recomendam que cada estabelecimento de beleza desenvolva um manual descrevendo as etapas do reprocessamento de materiais, incluindo a forma de limpeza, o preparo, o método de desinfecção e/ou esterilização desenvolvido, a forma de armazenamento, o prazo de validade, o teste de validação do processo de esterilização, e a manutenção dos registros de cada etapa de processamento (5).

A preocupação com processos de assepsia e esterilização inerentes aos procedimentos estéticos oferecidos em clínicas, centros e salões de beleza é cada vez maior, sendo levado em consideração que, na maioria dos casos, o cliente desconhece os riscos de infecções que poderão ocorrer pela utilização das terapias que evolvem o âmbito capilar, facial e corporal. Por isso, é de extrema importância a aplicação das medidas de biossegurança por parte dos profissionais, sendo elas voltadas para a prevenção, minimização e eliminação de possíveis riscos por contaminação de agentes microbianos (6). Geralmente, os microrganismos são transmitidos por contato direto ou indireto, através de gotículas de secreções respiratórias, ou pelo ar, sendo a transmissão por contato o meio de propagação mais relevante (7).

A microbiota normal da pele é dividida em residente e transitória, sendo que a residente é composta por colônias de microrganismos que se multiplicam e se mantêm em equilíbrio com as defesas do hospedeiro. Os microrganismos mais comuns desta microbiota são os estafilococos coagulase negativo, os micrococos e algumas espécies de corinebactérias. A microbiota transitória é composta por microrganismos que se depositam na superfície da pele, provenientes de fontes externas, colonizando temporariamente os extratos córneos mais superficiais. Esta microbiota normalmente é formada por bactérias gram negativas, como as enterobactérias, Pseudomonas sp., bactérias aeróbicas formadoras de esporos, fungos e vírus, possuindo maior potencial patogênico. Por serem facilmente removidos da pele, estes microrganismos são sensíveis aos processos de assepsia e se espalham com maior facilidade pelo contato. Os microrganismos presentes em infecções da pele, como 
em dermatoses ou abcessos, são classificados como microbiota infectante, e, nestes casos, os microrganismos envolvidos com maior frequência são os Staphylococcus aureus e os Streptococcus beta-hemolíticos. (7).

Sendo assim, este trabalho teve como objetivo avaliar o nível de informação que profissionais aplicadoras de maquiagem possuem, por meio da aplicação de um questionário abordando medidas de biossegurança inerentes às atividades realizadas. Além disso, determinar a presença ou ausência das bactérias potencialmente patogênicas Staphylococcus aureus e Pseudomonas aeruginosa em pincéis e esponjas utilizados em procedimentos de maquiagem, que foram fornecidos pelos estabelecimentos que responderam ao questionário.

\section{MATERIAL E MÉTODOS}

O estudo realizado foi uma pesquisa qualitativa de caráter experimental. A pesquisa envolveu a aplicação de um questionário para profissionais aplicadoras de maquiagens em salão de beleza e a análise microbiológica de artigos usados em procedimentos de maquiagem nos mesmos locais que responderam ao questionário.

Seleção dos estabelecimentos. Para a definição dos estabelecimentos participantes deste trabalho, primeiramente foi realizada uma pesquisa em uma rede social, na qual foram identificados prestadores de serviços de maquiagem no Município de Guaporé, RS. Após esta identificação, foi realizada uma consulta à Vigilância Sanitária Municipal, para que selecionasse entre os estabelecimentos identificados, aqueles que possuíam Alvará Sanitário vigente, que tivessem expediente entre $13 \mathrm{~h} 30$ e $17 \mathrm{~h} 00$, e que se localizassem no Bairro Centro de Guaporé, RS. Em seguida, os estabelecimentos que se enquadraram nesta seleção, foram contatados para consulta se aceitavam ou não participar da Pesquisa. Após esta consulta, ficou estabelecida a participação de cinco estabelecimentos, que foram identificados pelos números 1, 2, 3, 4 e 5, sendo que todos os responsáveis pelos estabelecimentos assinaram o Termo de Consentimento Livre e Esclarecido (TCLE).

Coleta dos artigos de maquiagem e aplicação de questionário. De cada estabelecimento, foi coletado um pincel para aplicação de rímel e um pincel ou esponja para aplicação de base, utilizados pelos profissionais maquiadores em seus clientes. No momento da coleta dos pincéis e da esponja, foi aplicado um questionário ao profissional maquiador de cada estabelecimento, a fim de verificar seu nível de informação com relação a ques- tões de biossegurança. As perguntas do questionário foram elaboradas tendo como base as referências técnicas da Agência Nacional de Vigilância Sanitária (Anvisa), aplicadas a estabelecimentos assistenciais e de interesse à saúde (8). O projeto foi enviado para avaliação e aprovação do Comitê de Ética e Pesquisa do Centro Universitário UNIVATES (COEP), sendo aprovado segundo o número 2.364.093.

Avaliação microbiológica dos artigos de maquiagem. Para a avaliação microbiológica do material amostrado, foram utilizados $\mathrm{NaCl}$ (Vetec), álcool $96^{\circ}$ GL(Synth), ágar Sal Manitol (SM) (Oxoid), ágar Cetrimida (Acumedia), água oxigenada (Dinâmica), corantes cristal de violeta, Lugol e Fucsina (LaborClin) e água purificada.

Do estabelecimento 1 foram processados um pincel de rímel e uma esponja para aplicação de base, e dos demais estabelecimentos (2, 3, 4 e 5) foram analisados dois pincéis, um para aplicação de rímel e outro para aplicação de base. Os artigos de maquiagem foram identificados por números e letras, sendo que o número é referente ao estabelecimento, as letras A e B são referentes ao pincel de rímel (incubação em duplicata) e as letras C e D são referentes ao pincel/esponja de aplicação de base (incubação em duplicata).

A técnica para a coleta de material microbiológico foi a de rinsagem. Em uma capela de fluxo laminar, foram coletados $50 \mathrm{~mL}$ de solução fisiológica $(\mathrm{NaCl}$ $0,9 \%$, previamente autoclavada, e repassados para um bequer. Após, o pincel foi mergulhado na solução, sendo agitado pelo período de 30 segundos. Depois deste procedimento, foram coletados $100 \mu \mathrm{L}$ da solução de rinsagem, e pipetados em cada placa de Petri, contendo os meios de cultura (ágar Sal Manitol e ágar Cetrimida) previamente solidificados. Movimentos circulares da placa garantiram a distribuição do material na superfície da placa. Após a inoculação em todas as placas de Petri, as mesmas foram levadas para uma estufa, onde permaneceram em incubação a uma temperatura de $37^{\circ} \mathrm{C}$ por 5 dias, com o intuito de favorecer o desenvolvimento de colônias bacterianas (9).

O ágar Sal Manitol contém alta concentração de sal, o que inibe o crescimento da maioria das bactérias. Staphylococcus aureus cresce neste meio e produz colônias com zonas amarelas devido à fermentação do manitol. No meio seletivo ágar Cetrimida, utilizado para a identificação de Pseudomonas aeruginosa, colônias positivas apresentam uma pigmentação característica azul ou azul esverdeada que se tornam fluorescentes sob a luz ultra- 
violeta de $254 \mathrm{~nm}$, pois esta bactéria produz tipicamente piocianina e fluoresceína (9).

Para a confirmação da presença de Staphylococcus, foi utilizada a prova bioquímica da catalase, que consiste na adição de uma gota de água oxigenada 3\% à colônia do microrganismo, com posterior formação de bolhas em caso de teste positivo (10). Ainda, foi realizada a microscopia das colônias, quando houve crescimento nas placas, através da técnica de coloração de Gram (9).

\section{RESULTADOS E DISCUSSÃO}

Todos os estabelecimentos contam com profissionais maquiadoras do sexo feminino, com idade entre 24 e 39 anos. Os estabelecimentos 1 e 5 contam com profissionais maquiadores com escolaridade de nível superior completo, enquanto os profissionais dos demais estabelecimentos possuem nível médio.

Os resultados do questionário aplicado estão descritos na Tabela 1.

Tabela 1. Proporção das respostas do questionário aplicado ao profissional prestador de serviço de maquiagem

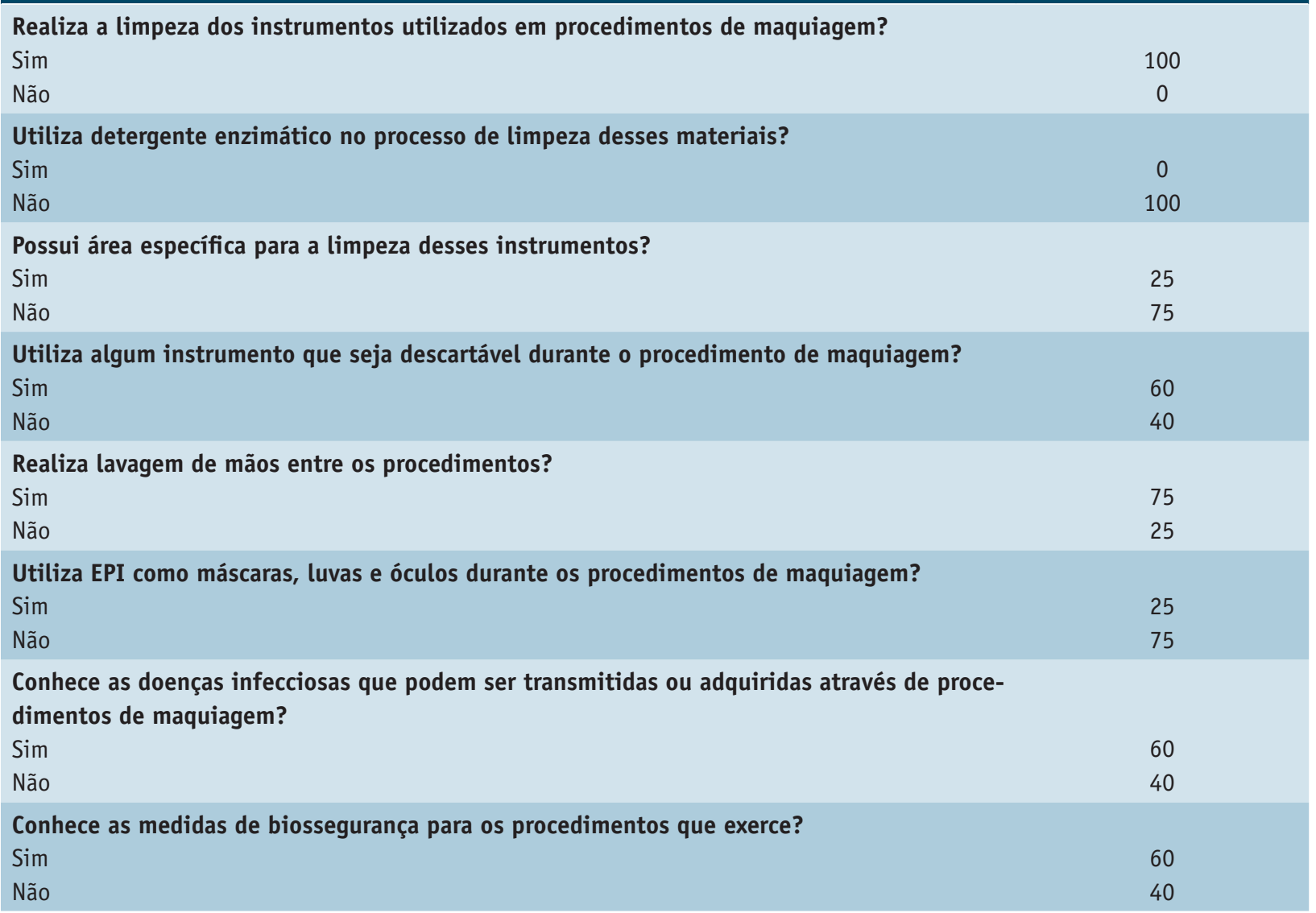

Ao analisar os resultados obtidos, $100 \%$ das entrevistadas declararam realizar a limpeza dos instrumentos utilizados nos procedimentos de maquiagem, porém, nenhuma delas utilizava detergente enzimático para limpar os materiais. O detergente enzimático é uma etapa muito importante no processo de limpeza dos materiais, pois remove possíveis camadas de biofilme, que neles ficam aderidas, facilitando o processo de desinfecção. Para limpeza das cerdas dos pincéis de maquiagem, as mesmas devem ser suavemente massageadas, a fim de retirar restos de produtos e sujidades, sendo que, pelo fato de serem delicadas, o produto de escolha para sua limpeza é o detergente enzimático, e na falta deste, xampus com fórmulas para cabelos (11). Segundo Ramos (2009) “os pincéis de maquiagem são de uso individual e, portanto, não podem ser reutilizados em outro cliente sem a devida limpeza e desinfecção" (11).

Apenas um dos estabelecimentos (25\%) possuía área específica para a limpeza do instrumental de maquiagem. Segundo a Referência Técnica para 
o Funcionamento dos Serviços de Estética e Embelezamento sem Responsabilidade Médica da Anvisa (8), o ambiente destinado ao processamento de artigos deverá dispor de pia com bancada para limpeza de materiais e bancada para o preparo, desinfecção ou esterilização de materiais, e quando não houver sala para processamento de material, esta atividade poderá estar localizada em uma área dentro da sala de procedimentos, desde que estabelecida barreira técnica (8). A importância da área específica ou de uma barreira técnica para o reprocessamento de materiais justifica-se principalmente pelo fato de evitar possíveis contaminações cruzadas, como por exemplo, por instrumentos processados em áreas contaminadas, como banheiros, copas, entre outros.

Ao serem questionadas com relação ao reprocessamento de materiais, $60 \%$ dos locais afirmaram utilizar algum tipo de instrumento descartável. Os artigos utilizados em procedimentos estéticos e de embelezamento devem ser submetidos aos processos de limpeza, desinfecção e esterilização, de acordo com o estabelecido em legislação específica e o Manual de Procedimentos Operacionais do estabelecimento. De acordo com a Anvisa, estes artigos, quando em contato com sangue ou secreções, devem ser esterilizados ou descartáveis (8). A pele é uma das barreiras biológicas mais importantes contra os microrganismos. Entretanto, quando os agentes infecciosos encontram quebra de integridade epitelial, ou quando inoculados diretamente por meio de instrumentais no organismo humano, encontram condições favoráveis ao seu desenvolvimento, iniciando um processo infeccioso, tais como conjuntivite e dermatoses (12). Alguns microrganismos não são eliminados no processo de limpeza e desinfecção e que instrumentos como pincéis de rímel, por exemplo, não são passíveis de esterilização, sendo em casos como este, necessário o uso de instrumentos descartáveis.

Com relação à lavagem de mãos, $80 \%$ das profissionais responderam que realizavam a lavagem de mãos entre os procedimentos, porém a mesma porcentagem não utilizava EPI como máscaras, luvas e óculos durante os procedimentos de maquiagem. As mãos constituem a principal via de transmissão de microrganismos durante a assistência prestada aos pacientes, pois a pele é um possível reservatório de diversos microrganismos, que podem se transferir de uma superfície para outra, por meio de contato direto (pele com pele), ou indireto, através do contato com objetos e superfícies contaminados. A higienização das mãos é a medida individual mais simples e menos dispendiosa para prevenir a propagação das infecções relacionadas à assistência à saúde (13). Ainda, a obrigatoriedade do uso de EPI é estabelecida para todos os trabalhadores brasileiros desde 1978 pela Norma Regulamentadora NR6 (14). No caso de riscos de contatos com material biológico, o uso dos EPI são uma medida universal, não restrita apenas aos profissionais de saúde, mas a todos que tenham a possibilidade de contato com sangue e outros líquidos corpóreos passíveis de transmissão microbiana (15). Não obstante, a não utilização de EPI pode explicar o fato de as esteticistas e cabeleireiras serem as profissões com maior risco de desenvolvimento de Dermatite de Contato Profissional (DCP), geralmente nas mãos, causadas principalmente por conservantes, como as isotiazolinonas, utilizados nos cosméticos, e causando dermatite alérgica de contato (16).

Ainda, $60 \%$ responderam que conheciam as doenças infecciosas que podem ser transmitidas ou adquiridas por meio de procedimentos de maquiagem e que também conheciam as medidas de biossegurança para o procedimento que exercem. Apesar de conhecerem os riscos aos quais estão expostas ou aos quais seus clientes podem se expor, a maioria das entrevistadas não fazia o uso de EPI durante os procedimentos. Contudo, mais do que a utilização de procedimentos adequados, a biossegurança ocupacional envolve questões éticas, morais e de responsabilidade social. Ao trabalhar com material infectante em desacordo com as normas de biossegurança, este profissional assume o risco do dano em potencial. Isso se justifica pelo fato de que um acidente pode causar agravos, tanto na saúde do trabalhador quanto na saúde do consumidor, bem como no trabalho ou na comunidade em geral. Segundo Cavalli e cols. (2015), "quando assume um risco, o trabalhador se expõe juntamente com a sua família, seus colegas de trabalho, seu ciclo social, bem como a sociedade como um todo" (17).

Com relação à pesquisa microbiológica, apenas as amostras provenientes da esponja de base do estabelecimento 1 (1C e 1D) e uma das amostras provenientes do pincel de base do estabelecimento 5 (5D) apresentaram crescimento de colônias no ágar sal manitol, sendo que no ágar Cetrimida não houve crescimento de colônias para nenhuma das amostras. As colônias das amostras 1C e 1D no ágar sal manitol apresentaram coloração rosada, enquanto a colônia da amostra 5D apresentava coloração amarelada, com o halo central alaranjado. A amostra $5 \mathrm{C}$, que teve a mesma origem da amostra $5 \mathrm{D}$, não apresentou crescimento, portanto o resultado da amostra 
5D foi considerado uma contaminação ocasional, não necessariamente vinda do material analisado, logo, foi desconsiderado. As colônias das amostras 1C e 1D apresentaram teste positivo para a catalase e na microscopia, apresentaram bactérias gram-positivas, com morfologia de cocos e com aspecto semelhante a cachos de uva, característicos de Staphyloccocus sp.

De acordo com o folheto informativo sobre o meio de cultura, o ágar sal manitol é utilizado para a coleta a partir de amostras clínicas e de cosméticos e medicamentos. Colônias com resultado positivo para o teste da coagulase, como o Staphyloccocus aureus, apresentam coloração amarela, não sendo o ocorrido para as amostras $1 \mathrm{C}$ e 1D. Colônias brancas com meio vermelho indicam a presença de Staphyloccocus epidermidis, provável microrganismo encontrado no material analisado.

Staphyloccocus epidermidis já foi considerado uma bactéria comensal inofensiva na pele humana. Atualmente, este microrganismo é reconhecido como um importante patógeno humano, relacionado principalmente com infecções associadas a dispositivos médicos residentes, ou seja, dispositivos que permanecem durante maiores períodos em contato com o paciente (18). Este microrganismo se tornou a principal causa de infecções nosocomiais da corrente sanguínea, bem como infecções oculares, auriculares, nasais, cardiovasculares e também de garganta. Ao contrário do Staphylococcus aureus, S. epidermidis tem apenas um número limitado de exotoxinas e exoenzimas degradativas, por isso, as infecções causadas por esse microrganismo são de natureza menos agudas e mais duradouras. Nestas infecções, o principal mecanismo de virulência de $S$. epidermidis é a formação de biofilmes (18).

O biofilme é um conjunto de células microbianas que formam uma fina camada (matriz) extracelular polissacarídica (EPS), camada que facilita a sua adesão a superfícies biológicas e também a interfaces sintéticas. Ele pode se formar em diversas superfícies, incluindo tecidos vivos, dispositivos médicos, sistemas de canalização de água, entre outros. As células bacterianas permanecem unidas umas as outras, às interfaces ou até mesmo aos substratos que circulam dentro dessa matriz. Essa matriz polimérica hidratada acaba dificultando os processos de desinfecção e esterilização de diversos materiais quando não são removidos adequadamente nos processos de limpeza. $(19,20)$. O biofilme pode ter relação com a contaminação dos instrumentos utilizados em procedimentos de maquiagem, pois estes, quando não são lavados adequadamente, podem favorecer o cresci- mento de microrganismos e a formação das EPS.

Com relação ao crescimento microbiano observado neste trabalho estar relacionado com a esponja utilizada no estabelecimento 1, este fato pode ter ocorrido por ela possuir uma área maior de contato com a pele e os cosméticos, aumentando a probabilidade de retenção de material e, por conseguinte, dificultando sua limpeza. Este resultado pode ser correlacionado com o questionário aplicado, pelo fato do estabelecimento 1 ter relatado não utilizar detergente enzimático no processo de limpeza de materiais, não possuir área específica para o processamento de materiais, e afirmar desconhecer as normas de biossegurança referentes à sua rotina. Ainda, apesar dos demais estabelecimentos apresentarem alguns riscos associados às respostas do questionário, não houve crescimento das bactérias de interesse nos materiais coletados. É importante considerar que a maior parte das amostras não apresentou crescimento nos meios seletivos, porém, outros microrganismos como fungos e outros tipos de bactérias, por exemplo, podem estar presentes nos pincéis. A presença de microrganismos, mesmo sendo não patogênicos, nos materiais de maquiagem pode vir a causar problemas caso houver uma proliferação exacerbada, ou ainda, se forem utilizados em ou por pessoas com sistema imune comprometido ou com lesões na pele. $\mathrm{O}$ fato de não ter ocorrido crescimento microbiano nos pincéis de alguns estabelecimentos também pode estar relacionado ao uso de conservantes na composição dos cosméticos utilizados nesta pesquisa.

Também é relevante considerar a veracidade das respostas do questionário, pois se tratavam de perguntas fechadas, sem necessidade de se aprofundar no tema. Apesar disso, não ocorreu crescimento dos microrganismos pesquisados em qualquer das amostras. $\mathrm{O}$ fato dos profissionais terem afirmado que os instrumentos são lavados, mesmo que tecnicamente de forma incorreta, pode ter levado a uma eliminação ou diminuição da contaminação dos materiais amostrados.

\section{CONCLUSÃO}

Ao avaliar as respostas do questionário, foi observado que há um entendimento parcial por parte das profissionais com relação às normas de biossegurança, pois mesmo que tenham relatado ter conhecimento com relação às doenças associadas ao serviço, nem sempre utilizam procedimentos corretos para evitar os riscos inerentes à atividade. Ao comparar as respostas do ques- 
tionário com o resultado do estudo microbiológico, pode ser concluído que, embora nem todas as recomendações técnicas sejam respeitadas, não houve o crescimento das bactérias patogênicas pesquisadas. Contudo, não se descarta a possibilidade de presença de outros microrganismos, como o Staphylococcus epidermidis, provável microrganismo encontrado na esponja de aplicação de base de um dos estabelecimentos.

\section{REFERÊNCIAS}

1. Cezimbra M. Maquiagem: Técnicas básicas, serviços profissionais e mercado de trabalho. Rio de Janeiro: Senac Nacional, 2013.

2. Garbaccio JL, Oliveira AC. O risco oculto no segmento de estética e beleza: uma avaliação do conhecimento dos profissionais e das práticas de biossegurança nos salões de beleza. Texto \& Contexto Enferm. 2013;22(4):98998. DOI: $10.1590 /$ S0104-07072013000400015

3. Teixeira P, Valle S. Biossegurança: uma abordagem multidisciplinar. 2.ed. Rio de Janeiro: FIOCRUZ, 1996.

4. Molento FHB. Biossegurança e a prática baseada em evidências. Rev Pan-Amaz Saude. 2017; 8(1):7-8. DOI: $10.5123 / \mathrm{S} 2176-62232017000100001$

5. Schwaab G, Lunkes JT, Jacob AM, Fermino N, Da Silva OM, Ascari RA. Reprocessamento de materiais em estabelecimentos de beleza. Rev Uningá. 2018;43(1):39283935. DOI: 20150501135811.

6. Garcia D, Moser DK, Betegga JMPR. Biossegurança nos salões de beleza de balneário Camboriú-Santa Catarina [acesso em 20 de dezembro de 2017]. Disponível em: http://siaibib01.univali.br/pdf/danielle\%20garcia-denise\%20moser.pdf

7. Santos AAM. Higienização das mãos no controle das infecções dos serviços de saúde. [acesso em 20 de dezembro de 2017]. Disponível em: http://www.anvisa.gov.br/ servicosaude/controle/higienizacao mao.pdf.

8. BRASIL. Ministério da Saúde. Agência Nacional de Vigilância Sanitária. Referência técnica para o funcionamento dos serviços de estética e embelezamento sem responsabilidade médica. Brasília; 2009 [acesso em 05 de janeiro de 2018]. Disponível em: http://portal.anvisa. gov.br/documents/33856/2054354/Refer\%C3\%AAn$\mathrm{cia}+\mathrm{t} \% \mathrm{C} 3 \% \mathrm{~A} 9 \mathrm{cnica}+$ para $+\mathrm{o}+$ funcionamento + dos + servi $\%$ C3\%A7os+de+est $\%$ C3\%A 9 tica+e+embeleza. mento + sem + responsabilidade $+\mathrm{m} \% \mathrm{C3} \%$ A9dica/e $37 \mathrm{a}-$ 023b-91c0-4f07-993a-393d041156ab.

9. BRASIL. Ministério da Saúde. Agência Nacional de Vigilância Sanitária. Farmacopeia Brasileira. São Paulo, 2010; 5.ed. 1:240-309.

10. Vieira DAP, Fernandes NCAQ. Microbiologia Geral. 2012 [acesso em 12 de setembro de 2017]. Disponível em: http://estudio01.proj.ufsm.br/cadernos/ifgo/tecnico_acucar_alcool/microbiologia_geral.pdf $>$.
11. Ramos JMP. Biossegurança em estabelecimentos de beleza e afins. São Paulo: Atheneu, 2009.

12. Soares RPM. Um olhar farmacêutico sobre as infecções por micobactérias. Pharmacia Bras. 2009; 12(71):21-28.

13. BRASIL. Ministério da Saúde. Agência Nacional de Vigilância Sanitária. Higienização das Mãos em Serviços de Saúde. Brasília, 2007; [acesso em 08 de fevereiro de 2018]. Disponível em: http://www.anvisa.gov.br/hotsite/ higienizacao_maos/manual_integra.pdf.

14. BRASIL. NR 6 - Equipamento de Proteção Individual - EPI. [acesso em 08 de fevereiro de 2018]. Disponível em: http://www.mte.gov.br/legislacao/normas_regulamentadoras/nr_06_pdf.

15. Siegel JD, Rhinehart E, Jackson M, Chiarello L. Healthcare Infection Control Practices Advisory Committee. Centers for disease control and prevention (CDC). Guideline for isolation precautions: preventing transmission of infectious agents in healthcare settings, 2007; [acesso em 08 de fevereiro de 2018]. Disponível em: https://www. cdc.gov/infectioncontrol/pdf/guidelines/isolation-guidelines.pdf

16. Subiabre-Ferrer D, Zaragoza-Ninet V, Ortiz-Salvador JM, Giacaman-von der Weth MM, Blasco-Encinas R, Sierra-Talamantes I. Dermatitis de contacto profesional, estudio clínico-epidemiológico entre los años 2011 y 2015. Med Segur Trabalho. 2016; 62(245): 318-326.

17. Cavalli LS, Karam FS, Brito KT, Brito BG. Existe relação entre ética e biossegurança ocupacional? Rev Contraponto. 2015; 1(3):176-180.

18. Vuong D, Gerke C, Somerville GA, Fischer CR, Otto M. Quorum-sensing control of biofilm factors in Staphylococcus epidermidis. J Infect Dis. 2003; 188:706-718. DOI: $10.1086 / 377239$.

19. Donlan RM. Biofilms: Microbial life on surfaces. Emerg Infect Dis. 2002; 8(9):881-889. DOI: 10.3201/ eid0809.020063.

20. Donlan RM, Costerton JM. Biofilms: survival mechanisms of clinically relevant microorganisms. Clin Microbiol Rev. 2002;15(2):167-193. DOI: 10.1128/ CMR.15.2.167-193.2002. 